\title{
A relação do movimento social com atores estatais no controle social sobre a política socioeducativa
}

Maria do Carmo Alves de Albuquerque*

\section{Resumo}

Analisamos a participação do movimento social de defesa dos direitos da criança e adolescente (movimento DCA) no controle social sobre a política socioeducativa, buscando caracterizálo, em diálogo com a literatura de movimentos e políticas públicas, na sua relação com a institucionalidade e a política pública. Notam-se repertórios de interação socioestatal que envolvem protestos, denúncias e também ações de negociação com o Estado. Destacase a formação de "coalizões" para a defesa do paradigma garantista, as quais envolvem atores societais e estatais, em grupos de trabalho que articularam juristas, membros dos Executivos e do movimento social para a elaboração do ECA, do Sinase e da política municipal socioeducativa, bem como nas articulações com o parlamento e com atores do Judiciário para a realização de CPIs e de fiscalizações das instituições denunciadas. 0s "repertórios de interação" e as "coalizões de defesa" são categorias analíticas utilizadas para a superação de uma perspectiva dicotômica, que vê a interação socioestatal como ameaça, propondose uma perspectiva interacionista que pensa movimento social e Estado como mutuamente constitutivos. 0 artigo é fruto de pesquisa, que analisou documentos de organizações do movimento, anotações de observação sistemática de suas reuniões e entrevistas com seus integrantes.

\section{Palavras-chave}

Movimento social. Repertórios de interação. Coalizões de defesa.

\section{Abstract}

We have analyzed the participation of the social movement for the defense of children and adolescents' rights (DCA movement) in social control over socioeducational policy in order to characterize it, taking into account the social movements and public policies literatures in their

\footnotetext{
* Professora e pesquisadora do Programa de Pós-graduação Mestrado Profissional Adolescente em Conflito com a Lei da Universidade Anhanguera (Unian) - São Paulo; e pesquisadora do Núcleo Democracia e Ação Coletiva (NDAC) do Centro Brasileiro de Análise e Planejamento (Cebrap). E-mail: mcarmoa@gmail.com.
} 
relationship with institutions and public policy itself. We identified the socioestatal interaction repertoires that involved protests, denunciations and also negotiations with the Executive. It was also possible to highlight the formation of "coalitions" for the defense of a guarantee paradigm involving societal and State actors in Working Groups that articulated jurists, Executives and social movement's members for the drafting of ECA, of Sinase, and municipal socio-educational policies as well as coordination with parliament and judiciary in order to perform CPIs and inspections of denounced institutions. The "repertoires of interaction" and "advocacy coalitions" are analytical categories used to overcome a dichotomous perspective, which sees interaction between society and State as a threat, proposing then an interactionist perspective that sees social movement and State as mutually constitutive. This research analyzed documents from movement organizations, and notes from systematic observation of meetings and interviews with their members.

\section{Keywords}

Social movement. Repertoires of interaction. Advocacy coalitions.

\section{Introdução}

Desde a Constituição de 1988, instituiu-se no Brasil uma arquitetura participativa com espaços de interação socioestatal, em que se definem as políticas públicas, principalmente na área social. Foram criadas conferências e conselhos paritários em todos os níveis de governo, com a função de exercer o controle social sobre as políticas públicas, atuando na definição de diretrizes e programas, na alocação de recursos, na avaliação e fiscalização de programas, na aprovação de contas, abrangendo as fases de planejamento, implementação e avaliação da política pública. Antes e para além dessas instituições participativas, as organizações de movimentos sociais lutaram cotidianamente por novas políticas de direitos. É essa incidência de atores sociais na política pública, tanto na sua criação e elaboração como na sua implementação, monitoramento e avaliação, que se entende aqui como o "controle social" sobre a política pública.

Essa gama de inovações democráticas se insere no amplo movimento de reconquista e ampliação da democracia, que se originou nas lutas contra a ditadura militar das décadas de 1960 a 1980. Insere-se, ainda, numa tendência mundial de criação de inovações de aperfeiçoamento da democracia, ligadas a novas exigências de transparência e prestação de contas e de maior participação dos cidadãos no controle do Estado e das políticas públicas 
(ISUNZA VERA; GURZA LAVALLE, 2012:118). A participação cada vez mais intensa dos movimentos sociais em novas arenas de controle social acentua a ação institucional dos movimentos e suainter-relação com oEstado.Analisamos neste artigo a participação do movimento social de defesa dos direitos da criança e adolescente (aqui chamado movimento DCA) no controle social sobre a política socioeducativa, buscando compreender e caracterizar, em diálogo com a literatura de movimentos e políticas públicas, a natureza desse movimento no que se refere à relação com a institucionalidade e a política pública. Enfocamos, principalmente, um segmento desse movimento social, a "Articulação dos Serviços de Medidas Socioeducativas em Meio Aberto de São Paulo", uma articulação informal entre as organizações sociais executoras dos Serviços MSE-MA".

Essa "Articulação", como veremos adiante, atua informalmente como parte do movimento DCA, mas é composta por organizações sociais institucionalizadas e conveniadas com o município de São Paulo para executar os Serviços de Medidas Socioeducativas em Meio Aberto, que são os programas constituintes da política municipal socioeducativa, voltada aos adolescentes infratores.

Para realizar essa análise, encontramos limites que colocaram a necessidade de ampliar o escopo teórico com o que geralmente se estudam as instituições participativas e o movimento social.

Por um lado, a participação cada vez mais intensa dos movimentos sociais nas arenas de interação socioestatal gera a necessidade de refazer leituras sobre eles, analisando as articulações entre os seus repertórios de ação institucional, na interação com atores estatais, e os repertórios de ação societal de confronto, mais frequentemente estudados pela literatura sobre os movimentos sociais.

Coloca-se ainda a importância de estudar a participação na sua relação com a política pública na qual incide, analisando a participação dos atores sociais numa chave que inclui os demais atores: o conjunto de atores sociais

\footnotetext{
${ }^{1}$ Como veremos adiante, os Serviços de Medidas Socioeducativas em Meio Aberto (Serviços MSE-MA) são serviços socioassistenciais definidos na Política Nacional de Assistência Social (PNAS), dentro da chamada "Proteção Social de média complexidade", e se destinam ao atendimento dos adolescentes infratores que cumprem as Medidas Socioeducativas em Meio Aberto, definidas pelo Estatuto da Criança e Adolescente (ECA, art. 112) como Liberdade Assistida (LA) e Prestação de Serviços à Comunidade (PSC). As Medidas Socioeducativas de privação de liberdade são de competência estadual, através das Secretarias de Justiça.
} 
e estatais envolvidos nos espaços de interação e controle socioestatais.

Neste artigo se busca realizar esse percurso para analisar como o movimento DCA interage com atores estatais na formulação e controle social sobre a política socioeducativa, notando-se entre eles uma mútua constituição. Busca-se mostrar onde e como, através dessas interações socioestatais, ele influi na política municipal socioeducativa.

O artigo é fruto de pesquisa docente realizada nos anos 2010 / 2012, com continuidade no momento atual. A metodologia utilizada incluiu pesquisa bibliográfica e documental voltada a caracterizar o Movimento DCA em São Paulo, envolvendo as atas dos Fóruns da Criança e Adolescente (DCA) e da Articulação dos Serviços de Medidas Socioeducativas em Meio Aberto de São Paulo. A pesquisa de campo envolveu entrevistas semiestruturadas com integrantes dessas organizações e acompanhamento com observação participante de espaços de controle social da política de direitos da criança e adolescente em São Paulo, a saber: Fórum Municipal DCA, Fóruns Regionais, Conselho Municipal (CMDCA) e Articulação dos Serviços de Medidas Socioeducativas em Meio Aberto de São Paulo. No caso da política de direitos da criança e adolescente, o controle social é realizado, segundo a legislação", tanto por meio dos Conselhos como das "organizações e articulações representativas" da sociedade civil ou da população, entre as quais incluímos a Articulação e os Fóruns.

\section{A incidência institucional do movimento na política DCA}

Quando aqui nos referimos ao movimento DCA, tomamos como base a definição de Diani (1992:1) de que "movimentos sociais são definidos como redes de interação informal entre uma pluralidade de indivíduos, grupos e/ ou organizações, engajadas em conflitos políticos ou culturais, com base em identidades coletivas compartilhadas". Assim, o movimento DCA se constitui numa pluralidade de organizações (ONGs, Fóruns etc.) e indivíduos que se engajam em lutas pela construção de um paradigma de direitos da

\footnotetext{
${ }^{2} \mathrm{O}$ controle social na política de direitos da criança e adolescente é realizado tanto por meio dos Conselhos como das "organizações e articulações representativas" da sociedade civil ou da população, conforme definido pelos artigos 227 e 204 da Constituição Federal, pelo ECA (art. 88) e pelas Resoluções 105 e 113 do Conselho Nacional - Conanda.
} 
Criança e Adolescente denominado "paradigma garantista" ou "doutrina da proteção integral”, e nas políticas públicas que o concretizam, desde o período Constituinte e de elaboração do Estatuto da Criança e Adolescente (ECA). É no processo de construção dessas concepções que o movimento constrói sua identidade. A concepção de Diani permite pensar o movimento como constituído de atores sociais distintos e heterogêneos, tanto aqueles mais informais - os que se autodenominam "movimentos" - como aqueles formalizados como ONGs, e, ainda, perceber que esse conjunto articulado de atores muda ao longo do tempo, assumindo distintas configurações em diferentes momentos de sua história de lutas.

Na análise da ação do movimento, dialogamos com algumas concepções desenvolvidas por Sidney Tarrow (2009) e Charles Tilly (2009). Tarrow situa os movimentos sociais dentro de processos políticos de "confronto" (2009: 18) - a "contentious politics", ações contenciosas, litígios, protestos ou lutas sociais. $\mathrm{O}$ autor pensa os movimentos como atores que se confrontam com opositores situados no universo estatal.

Para analisar as formas de ação do movimento Tilly (2009) desenvolve o conceito de repertório, considerando que os movimentos escolhem e aprendem formas de ação legitimadas por outros movimentos. As escolhas se dão pelo repertório de formas de ação já conhecido e também pela experimentação e combinação de práticas diversas em novas formas de se organizar, mobilizar apoio e articular demandas (TILLY, 1992; TARROW, 2009). O conceito está muitas vezes associado a "repertório de confronto", embora os movimentos sociais no Brasil não escolham apenas o confronto como forma ou estratégia de ação. É nesse sentido que Abers, Serafim e Tatagiba (2014, p.4) apresentam o conceito de "repertório de interação", buscando incluir diversas formas, práticas e estratégias de interação com o Estado entre aquelas escolhidas pelos movimentos para integrar o seu repertório.

$\mathrm{O}$ artigo olha para o movimento dentro do processo político de disputa com atores estatais e busca ampliar para além dos repertórios de confronto, examinando também seus repertórios de interação entre Estado e sociedade. Essa perspectiva recentemente explorada por autores brasileiros ${ }^{3}$ acentua a

\footnotetext{
${ }^{3}$ Entre os quais, Dowbor (2013), Carlos (2012), Sherrer-Warren e Lüchmann (2011), Tatagiba (2011), Almeida (2011). Estes autores, dialogando com a perspectiva teórica que enfatiza os repertórios de ação contenciosa (TILLY, 2010; TARROW, 2009), analisam os repertórios de ação institucional do movimento social.
} 
importância do estudo sobre a ação institucional dos movimentos sociais.

Os autores que analisam o movimento social pelos direitos da criança e do adolescente no Brasil ${ }^{4}$ situam o seu surgimento nas lutas sociais do período Constituinte e de aprovação do ECA.

No entanto, muito antes, ao revés de uma tradição que discrimina o "menor" abandonado e/ou infrator, relegando-o à iniciativa da benemerência privada e às políticas públicas de controle e punição, nota-se, em nível mundial, a presença de uma sociedade civil que incidiu na formulação de políticas públicas de garantia de direitos à criança e ao adolescente, buscando superar a perspectiva anterior, "menorista". O chamado paradigma menorista, também conhecido como "doutrina da situação irregular", caracterizase pela discriminação do menor, igualando órfãos, carentes e infratores como aqueles "em situação irregular", colocando-os preferencialmente em instituições de internação e sem reconhecer seu direito a um processo legal de julgamento.

Já no período pós-guerras, o problema do "menor" se torna grave o suficiente para que organizações de assistência reivindiquem políticas públicas mais abrangentes. São organizações sociais as que reivindicam e negociam junto às nascentes Nações Unidas o que vem a ser, em 1924, a Declaração de Genebra dos Direitos da Criança. Desde então diversos atores sociais e estatais interagiram de forma institucional na perspectiva de construir um paradigma de direitos da criança e do adolescente, o que se consolida como o novo "paradigma garantista" na Convenção da ONU sobre os Direitos da Criança e do Adolescente, em 1989. O paradigma garantista, também chamado "doutrina da proteção integral" se funda no reconhecimento da criança e do adolescente como sujeitos de direitos, abole a doutrina da "situação irregular", evita o confinamento em instituições fechadas e garante o devido processo legal aos adolescentes acusados de ato infracional.

No Brasil, os direitos da infância vão sendo debatidos e construídos no conflito e negociação entre sociedade e Estado, onde se destacaram, durante décadas, as denúncias contra os maus-tratos nas instituições "menoristas", a elaboração e a implementação de propostas alternativas ${ }^{5}$.

\footnotetext{
${ }^{4}$ Ver Pereira (1996), Lorenzi (2007), Palheta (2010) e Albuquerque (2012).

${ }^{5}$ Destaca-se a atuação do Legislativo em CPIs (Comissões Parlamentares de Inquérito), como a CPI do menor abandonado (1975) e os GTs de elaboração de propostas (PALHETA, 2010).
} 
O movimento DCA nasce no âmbito dos movimentos por direitos. Ele se articula no bojo dos movimentos sociais que emergem naslutas pela reconstrução da democracia, nos anos 70 e 90. A partir do Movimento Nacional dos Meninos e Meninas de Rua (MNMMR) e da Pastoral do Menor da Igreja Católica, e articulado com uma multiplicidade de outras organizações e indivíduos engajados na defesa dos direitos da criança e do adolescente ${ }^{6}$, surge um amplo movimento social, que se soma aos debates internacionais, avalia e denuncia a situação nacional, critica e elabora propostas para colocar a perspectiva "garantista" na Constituição Federal. Esses atores sociais, articulados com juízes, promotores e defensores públicos e outros atores estatais elaboraram, em 1987, a emenda popular "Criança Prioridade Nacional", e desencadearam a Campanha Nacional "Criança Constituinte", que coletou mais de 1,5 milhão de assinaturas em todo o país, originando os artigos 227 e 228 da Constituição, em que se expressa o paradigma garantista. Em 1988, constitui-se o Fórum Nacional dos Direitos da Criança e do Adolescente (FNDCA). O movimento se organiza desde então através de Fóruns de atores sociais, no plano nacional, estadual e municipal.

Atores societais e estatais também se fizeram presentes na Comissão para a Redação do ECA, onde, segundo Lorenzi (2007), houve a representação de três grupos expressivos: o "dos movimentos da sociedade civil”, o dos juristas (principalmente ligados ao Ministério Público) e o de técnicos de órgãos governamentais (notadamente funcionários da Fundação Nacional do BemEstar do Menor - Funabem).

Nesse período, porém, a atuação do movimento nos lugares institucionais de ação, como o Congresso Nacional, ainda era bastante informal, e os atores societais buscaram se fazer ouvir em negociações mais conflitivas ou nos diálogos mais "pacíficos" nos grupos de trabalho.

A Constituição e o ECA criaram instituições participativas de interação formal entre Estado e sociedade caracterizadas como espaços de controle social $^{7}$. Criaram-se Conselhos Tutelares, Conferências e Conselhos paritários

\footnotetext{
${ }^{6}$ Entre as ONGs que explicitam seu papel na defesa de direitos surgem os Cedecas - Centros de Defesa da Criança e Adolescente e a ANCED - Associação Nacional dos Centros de Defesa de Direitos de Criança e Adolescente. Ver http://www.anced.org.br/. Acesso em 25 de janeiro de 2014 .

${ }^{7}$ A Resolução 113 do Conanda diz em seu Art. 21. "O controle das ações públicas de promoção e defesa dos direitos humanos da criança e do adolescente se fará através das instâncias públicas colegiadas próprias, onde se assegure a paridade da participação de órgãos governamentais e de entidades sociais (...)".
} 
de Direitos com a função de desenhar, propor e fiscalizar as políticas públicas decorrentes do ECA, nos níveis municipal, estadual e nacional. Essa interação tem sido muito conflitiva, pois, entre outros entraves, boa parte da sociedade e dos atores estatais, especialmente as polícias e o poder judiciário, continuam bastante permeados por concepções menoristas. No entanto, as Conferências e Conselhos, especialmente o Conselho Nacional dos Direitos da Criança e do Adolescente (Conanda), têm sido responsáveis pela elaboração, negociação e aprovação de Resoluções que vêm lentamente desenhando políticas, instituições e procedimentos mais adequados ao paradigma garantista.

A política socioeducativa é um campo de ação ainda mais marcado pelo confronto. O movimento participou das lutas pela extinção da Febem de São Paulo, instituição socioeducativa marcada pela violação de direitos dos adolescentes. No final da década de 1990, adolescentes internos na Febem organizaram rebeliões, o movimento social realizou fiscalizações e apresentou denúncias até mesmo em fóruns internacionais, como a Corte Interamericana de Direitos Humanos da OEA. O movimento interagiu continuadamente com atores institucionais, como a OEA, o Parlamento brasileiro ${ }^{8}$, o poder Judiciário e o poder Executivo, especialmente o governador e a Febem. Ao lado das ações de confronto, o movimento DCA participou de grupos de trabalho (GTs) para elaborar propostas de descentralização da política socioeducativa.

Desde então, o movimento DCA vem participando do processo de construção da política socioeducativa com a criação do Sinase (Sistema Nacional de Atendimento Socioeducativo) através das Resoluções 113 e 119 do Conanda e também de uma política municipal socioeducativa em meio aberto em São Paulo - tanto na sua formulação como na sua implementação e avaliação, conforme veremos adiante.

Em toda essa trajetória vemos a incidência do movimento na política DCA. O movimento participou dos momentos em que a questão dos direitos da infância foi colocada na agenda pública, nos momentos de denúncias das práticas menoristas, na elaboração de propostas para a Constituição, o ECA, o Sinase e a política em meio aberto. Como dito, entendemos "controle social" como a incidência dos atores sociais na política pública, tanto na

\footnotetext{
${ }^{8}$ Destaca-se mais uma vez a atuação do Legislativo na CPI da Febem em 1987 (PALHETA, 2010).
} 
sua criação e elaboração como na sua implementação, monitoramento e avaliação. A legislação sobre controle social da política DCA considera as "organizações representativas" da população como responsáveis pelo seu exercício (Resolução 113 art. 14 §I), ao lado "das instâncias públicas colegiadas próprias" (art. 21).

Vimos que o movimento DCA exerce o controle social sobre a política DCA desde seus primórdios. As organizações do movimento lutaram pela nova política de direitos através de repertórios societais que se confrontaram com opositores estatais nas manifestações de denúncia das práticas menoristas do Estado na mídia e nas ruas. Por outro lado, o movimento desenvolve continuamente um "repertório de interação" com atores estatais, que tem ações propositivas em grupos de trabalho (GTs) que elaboram modelos para a política pública e ações de negociação que envolvem tanto o confronto como a concertação em torno da aprovação dessas propostas.

À medida que cresce a institucionalização democrática, com a criação de novas políticas, conselhos e conferências, os atores institucionais e os formatos institucionais de ação estão cada vez mais presentes nos movimentos. Com as tendências atuais de contratação de organizações sociais para a prestação de serviços, diversos atores tradicionais do movimento, como os Cedecas e outras ONGs, vêm assumindo a execução de programas da política DCA, especialmente na política socioeducativa em meio aberto.

Essa "institucionalização" dos movimentos sociais tem sido associada a problemas como a sua burocratização, o corporativismo e a cooptação, tanto pela literatura como por atores que os integram. Esses problemas

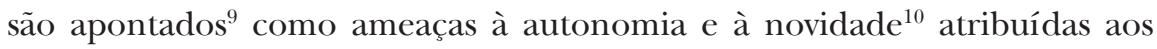
movimentos no processo de reconstrução e aprofundamento da democracia no Brasil.

No entanto, como detalharemos adiante, entre os atores sociais que executam programas públicos se notam distintas posturas frente às

\footnotetext{
${ }^{9}$ Ver debate que complexifica a relação entre cooptação e institucionalização dos movimentos DCA em Albuquerque (2012).

${ }^{10}$ Os chamados "novos movimentos sociais" foram saudados como inovações democráticas que escaparam da tutela do Estado. Como aponta Paoli (1995, p.27), os novos movimentos "não se referenciavam diretamente às estruturas institucionais de poder e representação política - partidos, governo, Estado - nem aos atores 'clássicos'”, no entanto, sua originalidade, sua novidade, encontrava-se na "aspiração de um poder civil e cidadão" em "escapar de uma institucionalidade estatal" que era "tutelar, autoritária e burocrática” (PAOLI, 1995, p.32).
} 
possibilidades de exercício do controle social. Algumas ONGs são mais ativas e outras se limitam à execução de programas, amedrontadas por problemas corporativos de sobrevivência financeira ou cooptadas pelo Estado ou partidos que, através de suas diretrizes, lhes reservam um papel instrumental.

González Bombal (2003, p.352), analisando a participação de organizações sociais em políticas para a criança e adolescente, aponta um "continuum que vai da participação com maior incidência", com organizações sociais "que participam nas diferentes fases [das políticas], com uma ampla capacidade de transformar não só o desenho e a formulação das políticas como garantir transformações nas orientações das políticas" até o extremo onde se encontram organizações "que limitam sua participação à implementação das políticas", com total dependência das diretrizes governamentais ${ }^{11}$.

Procuramos neste artigo analisar a ação institucional como um repertório permanente e constitutivo da ação dos movimentos que lutam por direitos e pelo seu reconhecimento através de políticas públicas. Os dilemas da ação corporativa ou cooptada pelo Estado ou partidos passam assim a ser vistos como intrínsecos e continuamente repostos nas várias situações da trajetória dos movimentos.

\section{Uma "coalizão de defesa" do paradigma garantista}

O controle social sobre a política DCA (e dentro dela a política socioeducativa) envolve necessariamente os repertórios de ação institucional. Colocase também a importância de analisar a relação dos atores sociais com os atores estatais e conhecer o conjunto dos atores que incidem na política pública. Enfatizamos aqui a importância de estudar o controle social na sua relação com a política pública na qual incide ${ }^{12}$, analisando a participação do movimento social como uma das partes interessadas (stakeholders) que atua na construção, implementação e monitoramento dessa política pública, como um dos atores que constituem a "comunidade" implicada nessa política. Para

\footnotetext{
${ }^{11}$ González Bombal analisa seis estudos de caso, na Colômbia, Argentina e Brasil.

${ }^{12}$ Dowbor (2013) analisa a relação do movimento sanitarista com a construção do Sistema único de Saúde (SUS) no Brasil. A autora destaca a importância de agregar a literatura sobre políticas públicas à literatura de movimentos sociais para melhor compreender a ação dos movimentos.
} 
tal se coloca a importância de agregar a literatura sobre políticas públicas à literatura de movimentos sociais.

Na literatura sobre políticas públicas, destacamos Kingdon (1995), que reconhece explicitamente que a configuração da ação dos atores é um elemento explicativo dos resultados em políticas públicas e Sabatier (2007), que analisa o papel dos setores ou "comunidades de políticas", constituídas pela diversidade de atores nelas implicados, na configuração da ação coletiva. Para tal, o autor destaca o papel das coalizões de "advocacy", ou coalizões de defesa, ou seja, as coalizões de múltiplos atores organizados em torno de crenças compartilhadas acerca de um subsistema de política.

No caso da política de direitos da infância e juventude, essas coalizões podem ser identificadas desde sempre. Notam-se coalizões que se articulam em torno de concepções de garantia de direitos e proteção integral assim como coalizões que permanecem "menoristas".

No primeiro caso, ao lado do movimento social, com seus múltiplos atores sociais (o MNMMR, a Pastoral do Menor, Sindicatos, ONGs, Associações de pediatras, de juízes, de advogados etc.), importantes aliados estatais atuaram no período Constituinte e de elaboração, negociações, aprovação e implementação do ECA. Entre eles se destacam juízes das varas da infância e juventude, defensores públicos, promotores, delegados, funcionários de instituições socioeducativas etc. No parlamento muitos integraram as coalizões que lutaram pelo novo paradigma atuando nas Comissões de Inquérito federais e estaduais (CPIs e CEIs) e nas Comissões de Direitos da Infância, que atuam em muitas câmaras legislativas.

A interação entre os atores sociais do movimento e os atores estatais é fonte de aprendizado mútuo, influenciando a construção de novos repertórios de ação institucional necessários para a incidência do movimento na política pública - para o exercício do controle social. As abordagens que ampliam o estudo do movimento na sua interação com atores estatais permitem uma melhor compreensão do controle social. Conforme Almeida (2011, p.13):

[...] essas abordagens sugerem a construção de um olhar que privilegie a fluidez das relações entre Estado e sociedade civil, os diversos modos pelos quais seus agentes interagem e se condicionam mutuamente, em distintos espaços e temporalidades.

Nas continuadas relações de interdependência entre os atores societais e estatais há um aprendizado recíproco que influencia crenças compartilhadas e repertórios de ação. Pode-se notar, emprestando a formulação de Dagnino 
(2011, p.124), que "sociedade civil e Estado são sempre mutuamente constitutivos".

\section{Controle social na política socioeducativa em meio aberto}

A política voltada para os adolescentes em conflito com a lei é alvo de históricas mobilizações da sociedade civil que luta por direitos humanos. Mesmo após a aprovação do ECA, as rebeliões na Febem de São Paulo, no final dos anos 1990, mostram a dificuldade em levar a esse setor da política pública o paradigma garantista. No entanto, elas foram um marco no processo de descentralização (MARTINS, 2011), com a criação de unidades de internação menores e o desenvolvimento das políticas socioeducativas em meio aberto ${ }^{13}$.

Diversas iniciativas de descentralização já ocorriam, desde os anos 70, como a Liberdade Assistida Comunitária (LAC), parceria da Febem com a Pastoral do Menor, e os "Polos de LA" da Febem nas diversas regiões do estado e na capital, também realizados em parceria da Febem com organizações sociais locais (CASA, 2010).

Através dessas parcerias, uma parte do movimento social DCA (como a Pastoral do Menor, alguns Cedecas e outras ONGs atuantes) se faz presente, atuando na implementação da política socioeducativa de liberdade assistida.

Hoje, em São Paulo, no caso dos 55 convênios para a execução do "Serviço de Medidas Socioeducativas em Meio Aberto", encontramos entidades que participaram historicamente das lutas sociais e embates pela criação do ECA, contra os maus-tratos na Febem e pela construção da política socioeducativa em meio aberto. Outras limitam sua participação à implementação dos programas.

\section{a. Articulação das organizações conveniadas na formulação da política}

A partir dos convênios com a Febem nos "Polos de LA" surge nesse período (1999-2000), uma "articulação" entre as organizações (ONGs) conveniadas

\footnotetext{
${ }^{13}$ As Medidas Socioeducativas em Meio Aberto (MSE-MA) são definidas pelo ECA (art. 112) e SINASE (art. 13 e 14) como Liberdade Assistida (LA) e Prestação de Serviços à Comunidade (PSC).
} 
com a Febem, entre as quais alguns Cedecas, que se torna decisiva para deflagrar o processo de municipalização na capital.

Em 2002, no governo da prefeita Marta Suplicy, essa "Articulação" integra uma comissão interinstitucional, incluindo Secretarias do Governo estadual e municipal (secretarias de educação e a SAS - Secretaria Municipal de Assistência Social), a Febem, o Unicef ${ }^{14}$, os Conselhos Municipais de Assistência Social (COMAS) e de Direitos da Criança e do Adolescente (CMDCA), Conselhos Tutelares e representantes do Ministério Público.

Forma-se, assim, uma coalizão de atores vinculados à política socioeducativa. Essa coalizão, ampliada através de convênio com a Secretaria Nacional de Direitos Humanos (SEDH), realiza diagnóstico dos adolescentes cumprindo medidas em São Paulo, elabora um modelo de atendimento ${ }^{15}$ e de capacitação de técnicos e implanta o novo modelo nos três distritos apontados pelo diagnóstico. Os três projetos-piloto são executados por atores sociais do movimento DCA, integrantes da "Articulação".

A coalizão que formulou esse primeiro modelo da política municipal socioeducativa foi integrada por atores sociais e estatais, entre os quais atores ligados a governos de partidos com orientações políticas distintas - a Febem, ligada ao governo estadual do PSDB, a SAS e a SEDH, ligadas a governos do PT. Apesar dessas diferenças, percebe-se que a coalizão se uniu na defesa das crenças que constituem o paradigma garantista, publicando uma sistematização desse processo intitulada "As Medidas Socioeducativas em Meio Aberto como garantia de proteção aos adolescentes e jovens da cidade de São Paulo" (SÃO PAULO, 2004, p.104), que evidencia essa identidade. É de se notar ainda que uma das principais lideranças da "Articulação" passou a coordenar o processo de elaboração e implantação da Política Municipal Socioeducativa na SAS, e que essa secretaria a institucionalizou como política integrante do Plano Municipal de Assistência Social (PLAS).

O processo sofreu alterações com os novos governos e seus distintos projetos políticos, mais ou menos comprometidos com a garantia de direitos

\footnotetext{
${ }^{14}$ Escritório regional do UNICEF - Fundo das Nações Unidas para a Infância em São Paulo.

${ }^{15}$ Esse modelo incluiu a medida de Prestação de Serviços à Comunidade (PSC) e outras ações, como a implantação do SIPIA II, sistema de informações para o acompanhamento das medidas em meio aberto e programas de profissionalização e de acompanhamento de egressos.
} 
sociais, mas a implantação paulatina do $\mathrm{SUAS}^{16}$ e do Sinase vem colocando novos parâmetros para a política pública na perspectiva do paradigma garantista.

A “Articulação dos Serviços de Medidas Socioeducativas em Meio Aberto (MSE-MA)", como hoje se nomeia, nascida em 1999, continua a reunir-se ao longo dos anos, com altos e baixos, para avaliar e melhorar os serviços prestados. É uma organização informal, com uma estrutura organizativa mínima ${ }^{17}$, integrada por organizações sociais juridicamente constituídas e conveniadas com a Secretaria Municipal - que passou a denominar-se Assistência e Desenvolvimento Social (SMADS). As entidades que executam serviços de MSE-MA atuam institucionalmente na execução dos serviços e eventualmente nos Conselhos (COMAS e CMDCA) e nas conferências dessas políticas públicas. Essas entidades, por outro lado, atuam com um repertório extrainstitucional - ou societal -, participando da Articulação e dos fóruns do movimento DCA.

Algumas delas, como o Cedeca Sapopemba, integram o movimento DCA desde as lutas pelo ECA e se posicionam claramente como "uma entidade de controle social". O Cedeca integra a executiva da Articulação e é uma entidade ativa no Fórum DCA regional de Sapopemba. Sua coordenadora, gerente do Serviço de MSE, afirma, sobre sua ação de controle social: "Os relatórios que a gente manda" para a prefeitura são instrumentos "de controle social". Cita ainda que, quando esses relatórios apontaram críticas, foram devolvidos para a retirada das críticas e que os técnicos do Cedeca foram discriminados por supervisores da SMADS, que "chegaram ao ponto de pedir aos [demais] gerentes para não se sentarem ao nosso lado”. A entrevistada apontou, porém, que algumas possibilidades permanecem, quando a supervisão é realizada por uma pessoa mais sensível e democrática, "que vem para construir". Nesse caso cita um resultado positivo em sua ação de controle social: em função de irregularidades apontadas em relatórios houve a abertura formal de "um procedimento verificatório".

\footnotetext{
${ }^{16}$ OSUAS, Sistema Único de Assistência Social, define responsabilidades nas ações socioeducativas em meio aberto, que são coordenadas pelos CREAS (Centros de Referência Especializada de Assistência Social).

${ }^{17}$ A pesquisadora acompanhou cerca de 12 reuniões da Articulação entre 2012 e 1013, das quais participaram uma média de 30 a 50 técnicos dos serviços MSE-MA do município. A "Articulação" possui uma Comissão Executiva com representantes das cinco regiões da cidade e um grupo de e-mails que repassa as atas das reuniões mensais aos participantes.
} 
Vemos assim que a Articulação e alguns de seus integrantes atuam no controle social da política DCA como atores do movimento DCA, com repertórios de ação institucional e societal, de confronto e de negociação. Elas atuam também no interior da comunidade de atores da política socioeducativa, formando uma coalizão de defesa do paradigma garantista.

\section{b. Uma triangulação na comunidade da política socioeducativa}

Vimos que a "Articulação" viveu relações com governos com projeto políticopartidários muito distintos ${ }^{18}$. A pesquisa aponta dificuldades de relação com os projetos e interesses políticos dos atores da "sociedade política" em todos os $\operatorname{casos}^{19}$ (ALBUQUERQUE, 2012, p.184). Entre essas foram especialmente difíceis as relações com os governos dos prefeitos José Serra e Gilberto Kassab, pioneiros no processo de privatização de políticas sociais ${ }^{20}$, em virtude de sua visão marcadamente neoliberal sobre o conveniamento. Essa visão minimiza o papel do Estado, reduzindo, no caso da política socioassistencial, os órgãos responsáveis pela política socioeducativa (os CREAS - Centros de Referência Especial de Assistência Social) a um mínimo de funcionários sem capacidade suficiente para a gestão e supervisão da política com apoio técnico às ONGs conveniadas.

A Secretaria Municipal (SMADS) que, como vimos, censurou relatórios, reprimiu a participação das entidades conveniadas em atividades do movimento e não reconheceu o papel da Articulação recusando o diálogo com ela $^{21}$. Durante 2012, em função da baixa capacidade da SMADS e dos CREAS em implementar as novas diretrizes do Sinase, os juízes da Infância e Juventude agiram em conjunto com a Articulação para pressionar o Executivo

\footnotetext{
${ }^{18}$ A Articulação atuou na relação com o PT dos governos de Marta Suplicy e atualmente de Fernando Haddad, mais comprometido com as políticas sociais e com o PSDB (prefeitos José Serra e Gilberto Kassab), que vem implantando em São Paulo a terceirização das políticas sociais numa perspectiva neoliberal.

${ }^{19}$ No caso do PT, as tensões geraram a renúncia coletiva dos representantes do CMDCA em 2004 e são citadas a formação de "chapas do PT" para concorrer às eleições do Conselho (ALBUQUERQUE, 2012).

${ }^{20}$ O governador José Serra, depois prefeito de São Paulo, instituiu na política de Saúde o convênio com OSS (Organizações Sociais de Saúde) e criou os "contratos de gestão" que transferem para organizações sociais a gestão de amplos segmentos da política social.

${ }^{21}$ Diversas organizações conveniadas relataram em entrevistas a repressão e ameaças em caso de participarem de fóruns, conferências e outras atividades do movimento DCA.
} 
municipal a avançar na política socioeducativa.

A Articulação reuniu-se diversas vezes com o DEIJ/SP (Departamento de Execuções da Infância e Juventude do Estado de São Paulo) ${ }^{22}$ para avaliar a situação das medidas judiciais (LA e PSC) que são cumpridas pelos adolescentes nos Serviços MSE-MA.

Nota-se, aqui, uma nova configuração da coalizão de defesa dentro da comunidade da política socioeducativa - desenvolvem-se interfaces socioestatais entre o movimento, o Judiciário e o Executivo, sendo que entre os dois primeiros há o compartilhamento de crenças e paradigmas.

\section{c. Elaborando modelos de intervenção socioeducativa}

Entre as medidas em meio aberto, a Liberdade Assistida (LA) incorpora elementos de conquista de direitos, como a escolarização e a profissionalização (ECA art. 119), além de incluir oficinas coletivas para o adolescente, voltadas à recuperação de autoestima, reinserção na família e na comunidade, orientações que não são definidas para a Prestação de Serviços à Comunidade (PSC) (ECA art. 117 a 119).

Assim, em São Paulo, o Judiciário orienta que, na execução da medida de PSC, o adolescente não tenha outros compromissos além das horas de serviços prestados a uma instituição pública ou privada da comunidade. Considera-se que convocar o adolescente para oficinas ou atividades de reflexão seja exigir dele mais do que as horas definidas na medida - seria mais do que o que lhe foi imposto pela autoridade judicial. Por outro lado, as instituições onde são prestados os serviços são fracamente envolvidas no processo, e em geral não se dedicam à relação com o adolescente que nelas vem trabalhar. Em função dessas causas existe uma avaliação, na Articulação, de que "o PSC não funciona", pois os adolescentes não permanecem o tempo determinado, descumprindo a medida, o que os leva frequentemente a receberem a imposição de outra medida.

Em função dessa situação, vários serviços de MSE-MA de São Paulo começaram a desenvolver um novo modelo de PSC - o PSC coletivo ${ }^{23}$. Esse

\footnotetext{
${ }^{22}$ O DEIJ é órgão criado pelo Tribunal de Justiça de São Paulo como órgão de justiça especializada na infância e juventude na área da execução das medidas socioeducativas.

${ }^{23}$ Em oficina de Sistematização de Boas Práticas realizada em novembro de 2013, foram analisadas três experiências de PSC coletivo que trabalham com pintura de grafitti em muros da comunidade, texturização de paredes, poesia, escrita e música.
} 
novo modelo reúne diversos jovens que estão cumprindo a medida de PSC, em alguns casos em conjunto com jovens cumprindo LA e outros jovens da comunidade. Eles recebem oficinas da técnica que vão trabalhar, por exemplo, o grafitti, e prestam o serviço de pintura de muros das instituições da comunidade que o desejarem. Embora sejam apontados aspectos negativos (como o abandono da medida por alguns jovens e a repressão do trabalho pela polícia), também foram apontados muitos resultados positivos, como o fato de jovens participantes serem contratados para executar o serviço profissionalmente. Apesar de algumas falhas, nota-se maior adesão dos adolescentes ao cumprimento da medida e, principalmente, uma nova relação dos jovens com a comunidade e com os demais serviços públicos (como saúde, educação e assistência social). Os educadores relatam que "Quem [na comunidade] já não falava com os meninos, começou a falar. Eram vistos como ladrões e essa visão mudou. Houve uma ressignificação do lugar deles na comunidade".

Assim como o PSC coletivo também temos o relato de um PSC cujo modelo foi desenhado na relação com a unidade pública de saúde onde os adolescentes foram cumprir a medida.

Esses exemplos são mais do que "boas práticas" - revelam que algumas organizações conveniadas mantêm seu papel crítico e formulador em relação à política pública.

Essa intervenção na política pública, a avaliação e o redesenho - na verdade desenho de um modelo de intervenção que ainda não estava definido -, só pode ser realizada por uma organização que executa a política e, ao mesmo tempo, é um ator social do movimento, compartilhando sua identidade e sua crença em paradigmas comuns acerca dos direitos do adolescente. Essa atuação se caracteriza como o controle social em três fases da política pública: as organizações que a implementam, a avaliam e são propositivas na elaboração de novos modelos de programas que a integram.

Ao contrário de atuações limitadas pela burocratização, cooptação ou corporativismo, perigos sempre presentes, vemos organizações que não se limitam ao mero papel acrítico de executoras (GONZÁLEZ BOMBAL, 2003) de um programa público, mas o recriam com o foco no paradigma garantista, que busca uma "ressignificação" do lugar do adolescente infrator na comunidade. 


\section{d. 0 Plano Municipal - articulação com o Conselho Municipal e Executivo}

Apontamos aqui uma atuação da Articulação que se dá em um plano maior - sua incidência na elaboração do Plano Municipal de Atendimento Socioeducativo, em conjunto com o Executivo municipal e o Conselho Municipal dos Direitos da Criança e Adolescente (CMDCA), ainda em curso.

A elaboração desse Plano é obrigatória em todos os níveis segundo o Sinase (BRASIL, 2012, art. 3, 4 e 5), com responsabilidade dos Executivos e conselhos respectivos.

O ECA (art. 88) define os Conselhos dos Direitos da Criança e Adolescente como "órgãos deliberativos e controladores" em todos os níveis, e o Sinase (art. 5) afirma que "Ao Conselho Municipal dos Direitos da Criança e do Adolescente competem as funções deliberativas e de controle do Sistema Municipal de Atendimento Socioeducativo". O Sinase define ainda que a política socioeducativa será gerida por Planos de Atendimento Socioeducativo, elaborados pela União, Estados e Municípios. Embora não cite explicitamente os Conselhos, eles devem exercer também nesse caso suas funções deliberativas.

O primeiro Plano Nacional foi aprovado em 2013 (BRASIL, 2013), mas diversos estados e municípios já elaboraram seus planos, cabendo agora a sua adequação ao Plano Nacional.

Ainda em 2012, a Articulação reuniu-se com o CMDCA, buscando incidir na elaboração do Plano Municipal. A partir de 2013, o Conselho, em um novo governo do PT, e presidido pelo representante do Executivo municipal, uma ex-liderança da Articulação ${ }^{24}$, assume papel determinante na elaboração do Plano.

Forma-se um grupo de trabalho integrado por representantes do Executivo e dos conselhos municipais (CMDCA e COMAS), e por representantes da Articulação. Esse grupo de trabalho passa então a coordenar o processo

\footnotetext{
${ }^{24}$ O CMDCA é presidido alternadamente por um representante da Sociedade Civil e do Executivo municipal. A partir de 2013, seu presidente é o representante da Secretaria Municipal de Direitos Humanos - Coordenador de Políticas para a Criança e o Adolescente, que foi integrante da Articulação nos seus primeiros anos. Disponível em: www.prefeitura.sp.gov.br/ cidade/secretarias/direitos_humanos/criancas_e_adolescentes/coordenacao. Acesso em 26 janeiro de 2014.
} 
de diagnóstico da situação municipal e a elaboração das propostas para o Plano.

Um dos primeiros entraves foi conquistar a adesão das secretarias da educação, saúde, assistência social, cultura, capacitação para o trabalho e esporte, que devem atuar na elaboração do Plano segundo o Sinase (art. 8). A Articulação está incidindo nessa elaboração, sistematizando suas avaliações das experiências de boas práticas e mobilizando educadores e adolescentes dos Serviços de MSE-MA para debater e incidir no Plano Municipal.

Mais uma vez, observa-se a articulação entre os repertórios societal e institucional desse segmento do Movimento DCA, bem como a constituição de uma coalizão de defesa do paradigma garantista, para incidir no controle social sobre a política socioeducativa municipal.

\section{Considerações finais}

Analisamos neste artigo o controle social sobre a política socioeducativa, enfocando, principalmente, um segmento do movimento social DCA - a "Articulação dos Serviços de Medidas Socioeducativas em Meio Aberto em São Paulo”, uma articulação informal entre as organizações sociais executoras dos Serviços MSE - MA.

As organizações que a integram, muitas das quais participam das lutas do movimento DCA desde os anos 70, são organizações formais conveniadas com a Secretaria de Assistência Social (SMADS) de São Paulo.

Apesar de a institucionalização do movimento social ser vista por muitos como ameaça à sua capacidade crítica e propositiva, o artigo apresentou exemplos de atuação da Articulação no controle social sobre a política municipal socioeducativa, na avaliação crítica, na proposição de modelos para a política socioeducativa, na elaboração do Plano Municipal Socioeducativo. Apresentou exemplos de inter-relação com o poder Judiciário no confronto com omissões do Executivo municipal e exemplos de atuação nos fóruns, espaços de articulação do movimento DCA.

IntegrantesdaArticulaçãoreconhecemperigoseameaçasdeburocratização dos atores sociais conveniados pelo excesso de "tarefismo", ou sobrecarga de tarefas burocráticas exigidas pelos convênios, pelo corporativismo posto pela contínua busca de recursos para a sobrevivência das instituições executoras dos serviços. Apontam ainda riscos de cooptação postos pela pressão dos 
projetos e interesses políticos do Estado e partidos ${ }^{25}$.

Apesar dos limites, ampliando-se o escopo com o que geralmente se estudam as instituições participativas, foi possível perceber a atuação desse segmento do movimento social DCA no controle social sobre a política socioeducativa.

Para tal, articulamos uma perspectiva teórica movimentalista com perspectivas que provêm da análise de políticas públicas. Por um lado, enfocamos os repertórios de ação dos movimentos, mostrando que se articulam repertórios de ações societais de confronto com repertórios de ações institucionalizadas de concertação entre Estado e sociedade. A teoria das políticas públicas traz os conceitos de comunidade setorial de políticas e de "coalizões de defesa", destacando a importância de analisar a participação política do movimento social numa chave que inclui os demais atores que com ele são partes interessadas em uma política pública.

Os resultados alcançados permitem enxergar o movimento social como um dos atores relevantes na formação e implementação da política pública socioeducativa. Sua participação ocorre na inter-relação com atores estatais que integram o conjunto de atores nela implicados: atores integrantes do Estado nos Executivos, Legislativos, no Judiciário e Ministério Público. Notam-se relações de interdependência entre os atores societais e estatais, o que corrobora a avaliação de Dagnino (2011, p.124) sobre o processo de mútua constituição entre sociedade civil e Estado.

\section{Referências}

ABERS, Rebecca; SERAFIM, Lizandra; TATAGIBA, Luciana.

(2014). Repertórios de interação EstadoSociedade em um Estado heterogêneo: a experiência na era Lula. Dados - Revista de Ciências Sociais, vol. 57, n.2, p. 325-357.

ALBUQUERQUE, Maria do Carmo Alves. (2015). 0 movimento pelos direitos da criança e adolescente e o controle social sobre a política socioeducativa: Repertórios de interação sócio-estatal. Revista Política \& Sociedade, 14, no. 29.
(2012). Novos atores e repertórios de ação no movimento pelos direitos do adolescente: repensando a institucionalização. Serviço Social em Revista, 15, n. 1.

(2007). A participação da sociedade na redefinição de políticas de direitos. Os direitos da Infância e o direito à moradia em países do Cone Sul na virada para o século XX. Tese de doutorado apresentada a Universidade de São Paulo.

\footnotetext{
${ }^{25}$ Esses problemas foram analisados por Adriano Oliveira (2013) e Albuquerque (2012).
} 
ALMEIDA. Carla Cecília Rego.

(2011). Sociedade civil, diversificação de atores e de modalidades de ação. Em Debate, 3, n.4, p.8-13.

BRASIL. Presidência da República.

(2013). Presidência da República. Secretaria de Direitos Humanos. Plano Nacional de Atendimento Socioeducativo: Diretrizes e eixos operativos para o SINASE. Brasília.

(2012). Presidência da República. Lei no 12.594, de 18 de janeiro de 2012. Sistema Nacional de Atendimento Socioeducativo - SINASE. Brasília.

(1990). Lei no. 8.069, de 13 de julho de 1990. Estatuto da Criança e do Adolescente. Brasília.

CARLOS, Euzeneia.

(2012). Movimentos sociais e instituições participativas: efeitos organizacionais, relacionais e discursivos nos padrões de ação coletiva. II Seminário discente da pósgraduação em Ciência Política da Universidade de São Paulo.

\section{FUNDAÇÃO CASA.}

(2010). Medidas Socioeducativas em Meio Aberto. São Paulo: CASA.

DAGNIN0, Evelina.

(2011). Civil Society in Latin America. In: Michael Edwards (Org.); The Oxford Handbook of Civil Society. Oxford: Oxford University Press.

DIANI, Mario.

(1992). The concept of social movement. The Sociological Review, Vol. 40, nº1.

DOWBOR, Monika.

(2013). Aarte da institucionalização: estratégias de mobilização dos sanitaristas (1974-2006). Tese de doutorado apresentada ao Programa de Pós-graduação em Ciência Política da Faculdade de Filosofia, Letras e Ciências Humanas da Universidade de São Paulo.

GOMES, Maria do Rosário Corrêa de Salles.

(2012). A relação SUAS/SINASE na execução das medidas socioeducativas em meio aberto: notas para debate. Gestão da política de direitos ao adolescente em conflito com a lei. Wilson Liberati (coord.) São Paulo: Letras Jurídicas.

GONZÁLEZ BOMBAL, Inés.

(2003). Organizaciones de la Sociedad Civil e incidencia en políticas públicas: reflexiones para seguir avanzando. In: Inés Bombal González; Rodrigo Villar (Compiladores); Organizaciones de la Sociedad Civil e incidencia en políticas públicas. Buenos Aires: Libros del Zorzal.

ISUNZA VERA, Ernesto; GURZA LAVALLE, Adrián.

(2012). Arquitetura da Participação e controles democráticos no Brasil e no México. Novos Estudos. São Paulo: Cebrap.

KINGDON, John Wells.

(1995). Agendas, Alternatives, and Public Policies. New York: Harper Collins College Publishers.

LORENZI, Gisella Werneck.

(2007). Uma Breve História dos Direitos da Criança e do Adolescente no Brasil. Disponível em: http://www.promenino.org.br. Acesso em 23 de janeiro de 2014.

MARTINS, Rose Iracema Martim Garcia.

(2011). SIG - Sistema de Informação de Gestão da Fundação CASA: um instrumento para tomada de decisões. Dissertação de mestrado apresentada ao Programa de Pós-graduação Profissional em Adolescentes em Conflito com a Lei da Universidade Bandeirantes. Brasil, São Paulo.

McADAM, Doug; Charles TILLY; Sidney TARROW. (2009). Para mapear o confronto político. Lua Nova, 76, p.11-48.

OLIVEIRA, Adriano Basilo Pereira.

(2013). O papel das organizações conveniadas no controle social sobre a política socioeducativa em meio aberto em São Paulo. Dissertação de mestrado apresentada ao Programa de Pós-graduação em Mestrado Profissional em Adolescente em Conflito com a Lei da Universidade Bandeirante. Brasil, São Paulo. 
PALHETA, Adriana.

(2010). Sociedade Civil, Direitos Humanos e Adolescente em Conflito com a Lei. Dissertação de mestrado apresentada ao Programa de PósGraduação Mestrado Profissional Adolescente em Conflito com a Lei da Universidade Bandeirante. Brasil, São Paulo.

PAOLI. Maria Célia.

(1995). Movimentos Sociais no Brasil: Em busca de um estatuto político. In: Maria Célia Pinheiro Machado Paoli; Michaela Hellman (Orgs.); Movimentos sociais e democracia no Brasil. "Sem a gente não tem jeito". São Paulo: Editora Marco Zero / ILDESFES - Instituto Latino-americano de Desenvolvimento Econômico e Social.

PASTORAL DO MENOR.

(2010). Liberdade Assistida: Um projeto em Construção. Belo Horizonte: Pastoral do Menor.

PEREIRA, Rosemary Ferreira de Souza.

(1996). Movimento de defesa dos direitos da criança e do adolescente: do alternativo ao alterativo. Dissertação de mestrado apresentada ao Programa de Pós-graduação em Serviço Social da Pontifícia Universidade Católica de São Paulo.

PINI, Francisca Rodrigues de Oliveira.

(2006). Fóruns DCA: fios que tecem o movimento da infância e da adolescência na construção de caminhos para a democracia participativa. Tese de doutorado apresentada ao Programa de Pós-graduação em Serviço Social, Pontifícia Universidade Católica de São Paulo.

São Paulo. Secretaria Municipal de Assistência Social (SAS).

(2004). As medidas Socioeducativas em Meio Aberto como garantia de proteção aos adolescentes e jovens da cidade de São Paulo. São Paulo: SAS eSecretaria Especial de Direitos Humanos da Presidência da República.
(2003). Plano de Assistência Social da Cidade de São Paulo (PLAS 2002-2003). São Paulo: SAS.

SABATIER, Paul Armand.; WEIBLE, Christopher. (2007). The Advocacy Coalition Framework: innovations and clarifications. In: Paul Sabatier (Ed.); Theories of Policies Process. Boulder, Colorado, US. Westview Press. p. 189-222.

SCHERER-WARREN, Ilse; LÜCHMANN, Lígia Helena Hahn.

(2011). Movimentos sociais e participação institucional: introduzindo o debate. Política e sociedade, 10, n. 18.

TARROW, Sidney.

(2009). O poder em movimento. Movimentos sociais e confronto político. Petrópolis: Editora Vozes.

TATAGIBA, Luciana.

(2011). A questão dos atores, seus repertórios de ação e implicações para o processo participativo. In: Roberto Pires (Org.); Efetividade das instituições participativas no Brasil: estratégias de avaliação. (Diálogos para o desenvolvimento v.7). Brasília: IPEA.

TILLY, Charles.

(2010). Movimentos sociais como política. Revista Brasileira de Ciência Política, no 3. Brasília, p.133-160.

\section{Recebido em}

janeiro de 2014

\section{Aprovado em}

fevereiro de 2015 